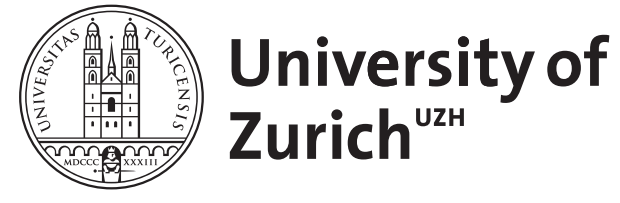

Zurich Open Repository and Archive

University of Zurich

University Library

Strickhofstrasse 39

CH-8057 Zurich

www.zora.uzh.ch

Year: 2019

\title{
The gothic at the heart of film and film theory
}

Bronfen, Elisabeth

Posted at the Zurich Open Repository and Archive, University of Zurich

ZORA URL: https://doi.org/10.5167/uzh-170560

Book Section

Published Version

Originally published at:

Bronfen, Elisabeth (2019). The gothic at the heart of film and film theory. In: Hogle, Jerrold E; Miles, Robert. The gothic and theory: an Edinburgh companion. Edinburgh: Edinburgh University Press, 165-180. 
The Gothic and Theory 


\section{Contents}

Edinburgh University Press is one of the leading university presses in the UK. We publish academic books and journals in our selected subject areas across the humanities and social sciences, combining cuttingedge scholarship with high editorial and production values to produce academic works of lasting importance. For more information visit our website: edinburghuniversitypress.com

(C) editorial matter and organisation Jerrold E. Hogle and Robert Miles, 2019

(C) the chapters their several authors, 2019

Edinburgh University Press Ltd

The Tun - Holyrood Road

12(2f) Jackson's Entry

Edinburgh EH8 8PJ

Typeset in 11/13 Adobe Sabon by IDSUK (DataConnection) Ltd, and printed and bound in Great Britain

A CIP record for this book is available from the British Library

ISBN 9781474427777 (hardback)

ISBN 9781474427791 (webready PDF)

ISBN 9781474427807 (epub)

The right of Jerrold E. Hogle and Robert Miles to be identified as the editors of this work has been asserted in accordance with the Copyright, Designs and Patents Act 1988, and the Copyright and Related Rights

Regulations 2003 (SI No. 2498).

\section{Acknowledgements}

1. The Gothic-Theory Conversation: An Introduction Jerrold E. Hogle

\section{Part I: The Gothic, Theory and History}

2. History/Genealogy/Gothic: Godwin, Scott and their Progeny

Robert Miles

3. The Gothic in and as Race Theory Maisha Wester

4. Postcolonial Gothic in and as Theory Alison Rudd

Part II: The Gothic of Psychoanalysis and its Progeny

5. The Gothic Body before and after Freud Steven Bruhm

6. Abjection as Gothic and the Gothic as Abjection Jerrold E. Hogle

Part III: Feminism, Gender Theory, Sexuality and the Gothic

7. Unsettling Feminism: The Savagery of Gothic Catherine Spooner

8. Gothic Fiction and Queer Theory George E. Haggerty 


\section{Part IV: Theorising the Gothic in Modern Media}

9. The Gothic at the Heart of Film and Film Theory Elisabeth Bronfen

10. Techno-Terrors and the Emergence of Cyber-Gothic Anya Heise-von der Lippe

Part V: The Gothic before and after Post-structuralism

11. The Gothic as a Theory of Symbolic Exchange David Collings

12. Incorporations: The Gothic and Deconstruction Tilottama Rajan

13. Dark Materialism: Gothic Objects, Commodities and Things Fred Botting

14. Thinking the Thing: The Outer Reaches of Knowledge in Lovecraft and Deleuze Anna Powell

15. Gothic and the Question of Ethics: Otherness, Alterity, Violence

Dale Townshend

Part VI: The Gothic-Theory Relationship in Retrospect and Prospect

16. On the Threshold of Gothic: A Reflection David Punter

Notes on Contributors

Index

The editors are deeply grateful, first, to Professors William Hughes and Andrew Smith, the General Editors of the Edinburgh Companions to the Gothic, for inviting us to put this collection together and for supporting us in, and counselling with us on, this effort in every way they could. We are immensely appreciative, too, of all our contributors, every one of whom seized insightfully on our approach to the Gothic-andtheory conversation and provided expert analyses in their areas of greatest knowledge in ways well suited to the readership anticipated for Edinburgh Companions. We know that these scholars, world-class Gothicists and theoreticians all, often had to carve out time from busy and demanding lives to write these essays, and we thank them all for working back-and-forth with us, and even giving us some good ideas that we had not considered at first, to achieve the results that we are happy and proud to present to our readers. Both we and our contributors, in addition, are grateful to our universities, and often to key staff members within them, for their steady support of our work on the Gothic and theory. We also happily acknowledge, all of us, the indispensable help offered to us by our families - and our spouses or most significant others in particular. Finally - after saluting and appreciating each other, to be sure - we send our thanks to Edinburgh University Press, and especially to our main editorial facilitator, Ersev Ersoy, for all their encouragement, special consideration and professional expertise. We feel privileged to have been asked to envision and to have brought together this Gothic and Theory volume in the Edinburgh Companions to the Gothic series. 


\title{
The Gothic at the Heart of Film and Film Theory
}

\author{
Elisabeth Bronfen
}

While Don Draper, the ad-agency 'creative director' in the American television series Mad Men (2007-15), is best known for a self-reliance that often helps him to recover from personal and professional setbacks, he is also a haunted man. Since the identity theft on the Korean War front that led to the burial of his CO under a false name, Dick Whitman (Don's original name) has been living a double life. Even after he has succeeded in becoming a celebrity in the Madison Avenue world of advertising, this secret past continues to have a hold on him. Thus, while series creator Matthew Weiner has garnered praise for his accurate reimagination of American culture in the 1960s, Gothic moments that render visible Don's haunting by his former self trouble what is otherwise an artful revisitation of Hollywood's office-film genre of the 1950s-1970s. Visually performing the disturbance of the ordinary so prototypical of a Gothic sensibility, these moments not only speak to the psychological consequences of Don's duplicitous existence, they also draw attention to my subject here: what is Gothic about any filmic representation, namely that its doubling of the world on screen - developing the Gothic penchant for doubles in an especially visual manner - is always predicated on a spectral play between absence and Gothic presence.

In contrast to the way Don recalls his war experiences, an ominous mood permeates those Mad Men flashbacks that reveal the destitution and moral depravity of his childhood and adolescence. These include the death of his mother and the stillborn child of Abigail Whitman, whose place he assumes in the family of his biological father, and the fatal injuring of his father by his horse while he was attempting to mount it in a drunken state. While the dark colours in which these memory scenes are cast underscore the contrast with Don's apparent good fortune, his imaginary resuscitation of these 
phantoms of the past seeps into the places he currently inhabits, rendering his ordinary world uncanny. As the editing moves between these two temporal moments, the past sense of foreboding does more than displace all sense of security. This visual splice renders Don's present a ghostly space as well, the backdrop for the far more powerful recollections that cannot be contained. In that Don assumes a spectral presence in these reimagined scenes, neither fully in the past nor in the present but rather hovering between the two, selfreflexivity comes into play. In relation to the camera as the device producing these hallucinations, his remembering eye/I is the point of interconnection between actual experience and spectral recollection.

Even more markedly Gothic are those sequences in which the dead make an appearance as ghosts, bearing an encrypted message regarding the precarious state of Don's double existence. After his real brother, Adam, has committed suicide because Don refuses to let him be part of his new life, his apparition returns more than once - an embodiment of a murky sense of guilt but also a figure of warning. More felicitous, yet equally Gothic, is the moment when Anna Draper, the wife of the man whose identity Don has assumed, appears in the office where he has fallen asleep on a sofa while he waits for a call from California to say she has died. A translucent figure, Anna enters with a suitcase in her hand, and, as if looking for him, scans the room. Her steps wake him up, and, once their eyes meet, she smiles at him before turning away to leave him again. In a similar spirit, his former lover, Rachel Menkin, appears to him in a scene that recalls the casting session with which the episode 'Severance' (Season 7) begins. Wearing only a fur coat, she first poses in front of a mirror, similar to the other models, but then turns towards Don, explaining that 'I am supposed to tell you, you missed your flight.' Only later will Don discover that she, too, has died. The scene begins with Ted opening the door to let Rachel in, but closes with Pete telling Don that it is time to get back to work. Her apparition is weird in a manner reminiscent of the Gothic films and television series of David Lynch; rather than being staged as a hallucination, it is presented as an alternate reality into which Don enters in his sleep.

The narrative climax of these spectral visions has, however, already occurred in 'A Tale of Two Cities' (Season 6), when Don, intoxicated during a party in California, has his own near-death experience. The comment made by a spectral one-armed soldier he espies among the guests - 'dying doesn't make you whole, you should see what you'd look like' - prompts a vision of himself, standing at the edge of a pool, looking down at his own corpse. Seconds later, we see him resuscitated by Roger, who has pulled him out of the pool. The doubling of his body, one alive and the other dead, again reflects on the precarious duplicity of his current existence by having recourse to a Gothic sensibility. As messengers from the past, all these apparitions serve as a form of self-knowledge. They call upon Don to acknowledge that, because he is always in flight, running as much from the constraints of the ordinary as from a past life he does not want to relinquish, he is himself living a ghostly existence.

By rendering visible the threat that looms beneath the surface of the stylish world that Draper is passing through, the filmy dead who have returned to the world of the living point, in extradiegetic terms, to the fault lines in the optimism so pervasive in post-war American culture. Yet these Gothic interpolations have a message for us in a further sense, embodying the spectral force on which any historical reimagination is grounded. By virtue of having recourse to montage as a cinematic device that splices together different moments in time, introducing the past back into the present, these markedly Gothic moments allow Mad Men to think about its own aesthetics. Don, lying on the edge of the pool, once more gasping for breath, can be read as a trope for the entire show's project, predicated as it is on drawing attention to the way the past is never gone. Instead, the haunting past overshadows and even encroaches on the world of the early twentyfirst century, cinematically as well as narratively (see Bronfen 2016 for more on Mad Men).

To explore the Gothic at the heart of film theory thus entails focusing on the correspondences between a thematic concern with the presence of death in life and the cinematic work used to perform and transmit such disruptions of our ordinary experience of the world. The claim of this essay, building mainly on some insights from Stanley Cavell (who argues that cinema satisfies our magical wish to view a world on screen from which we are absent, unseen), is that film is most markedly self-reflexive when it involves stories of haunting because these speak to the fact that there is something inherently ghostly about cinema itself (see Cavell 1979). The Gothic as a mode in fiction, after all, arose under the influence of, and also influenced, the phantasmagoric magic-lantern shows of the eighteenth century that vividly projected spectral figures from the past, often to arouse fear, on to screens or walls or even darkness itself (Castle 1995: 140-67), very like the old portrait that walks out of its frame into the air in Horace Walpole's The Castle of Otranto (1764), the first narrative to call itself 'a Gothic Story'. Playing with and to our fascination with bringing what has disappeared back to life by rendering the past 
present again, albeit as embodied visions, the technical devices of modern cinema quite self-consciously bank on the affective effect of haunting just as their magic-lantern ancestors did. Even if the actors in a given film story are not dead, they are of course not actually present to us. Given the importance that lighting and the cadrage (the director's viewfinder) have for their existence as film images, they are also never the same on screen as in reality. We are, thus, always seeing after-images of people, things and spaces, manipulated to tell a particular film narrative.

Furthermore, what is rendered present again are not living people, but rather moving images that double and stand in for them. Affected by these apparitions, we see and experience film characters and the world they inhabit as animate even as we know them to be nothing other than a spectral illusion. As such, cinema renders fluid the boundary between actual/corporeal and imaginary/psychic experience. The magic of cinema consists in eliciting an uncanny ambivalence of response. The bodies that appear to us are spectres, yet they have a somatic impact on us. We are drawn in and affected by a conjured image world not although but because we know it to be a technical manipulation of our sight. Cinema's power of resuscitation affects objects as well in an ambivalent manner. Like Gothic spectres, filmed objects take on a life of their own. In the process of being animated, they not only reflect on cinema as the art of endowing still images with life. They also draw attention to the way that lighting, framing and mise-en-scène can have the opposite effect, namely that of transforming living bodies into inanimate signs. The logic of classic shot/reverse shot editing is such that, detached from the body by virtue of montage editing, an eye and the object on which its gaze focuses not only appear on the same diegetic level of the film but are both inanimate images on film, albeit in motion.

The affective ambivalence at issue is such that, by assuming the position of the camera in the act of viewing a film, we can use our imaginary capacities, like a Victor Frankenstein, to animate what is absent or lifeless. By the same token, too, we are partaking in a process that renders the world inanimate, freezing it into moving images of fragmented and spliced bodies. The spectral play between presence and absence, on which the illusory power of cinema is predicated, is thus doubled by an equally uncanny exchange between animation and de-animation. If, in turn, the film image doubles the movie star playing a fictional character, this duplication implicates us as well. Insofar as sharing in the phantasmagoria involves projecting myself on to and empathising with, not just a stranger, but one who is the effect of cinematic devices, this whole process, like magiclantern shows, entails a moment of self-destabilisation. The power of my imaginary capacities consists in allowing me to experience something as phenomenologically real to which, in fact, I am absent. This means, however, that, at least for the period of my engrossment in a given film, I am absent to myself, absorbed instead in the emotion be it fear, suspense or excessive enjoyment - enacted on screen.

Regarding the correspondence between Gothic concerns and cinematic devices, it is useful to recall Sigmund Freud's discussion of the uncanny, related as it is to a return from repression that arouses dread and horror. He significantly bases his analysis of the types of situations that arouse in us the feeling of uncanniness on the claim that 'beimlich is a word the meaning of which develops in the direction of ambivalence, until it finally coincides with its opposite, unheimlich' (Freud 1955: 226). Such a blurring of distinctions is key for the viewing effect on which the ghostly quality of cinema is predicated because it creates an ambivalence regarding whether what emerges on screen is present and/or absent, bodily and/or psychic, real and/or imagined, alive and/or dead. Consequently, it is precisely this intellectual uncertainty that speaks to why the Gothic is at the heart of cinema's self-reflection. Particularly the phenomenon of the double, singled out by Freud, involves epistemological hesitation when rethought in terms of cinematic effect. Imaginary reduplication may, as Freud demonstrates, include sharing knowledge, feelings and experiences with someone who is considered identical to oneself, such as when we empathise with a film character to the extent that she or he is perceived as an extension of ourselves. Or it may involve the self-doubt that arises from this identification, namely when, in extreme situations, we are cajoled into completely substituting the film character for ourselves. In either case, the doubling, dividing and interchanging at issue involve a blurring between me and the other, here and there, being and not being.

However, the double also touches on cinema's concern with reanimation in another sense. As Freud points out, while guardian spirits and a belief in the afterlife of the soul allow for the double to be conceived as 'an assurance of immortality', its reverse aspect transforms this figure into 'the uncanny harbinger of death' (Freud 1955: 235). For Freud, the ambivalence between sustainability and disappearance of the self that is negotiated with the use of a double speaks to the human capability for self-observation and self-criticism. Detached from the rest of the ego, the mental part of ourselves, by offering reactive comments, affords insights into ourselves that are not possible 
through direct experience. Reconceiving all this in terms of cinematic language, one can say that, along with a blurring of the boundary between absence and presence, in-animation and re-animation, movies make use of the technical ability to double characters such that they can be in two places at once - acting and observing themselves act. At the same time, by virtue of our absorption in the cinematic spectacle, we also find ourselves split between an imaginative empathy with the world being viewed and an intellectual distance from it. We also become a double of ourselves in that, at one and the same time, we emotionally indulge in and intellectually observe what is facing us on the screen.

If Freud, in turn, privileges the fear of damaging or being robbed of one's eyes for his discussion of the uncanny, an alteration of vision pertains to the spectral logic of cinema as well. While all moving images perform ocular manipulation, it is precisely when the camera and the editing translates a Gothic concern with excessive emotions into an extreme visual distortion that one can speak of an 'assault on our eyes'. Such reanimism is as ambivalently marked as other Gothic motifs, not least because it serves as the source for an omnipotence of thoughts crucial to any emotional transference between a spectator and characters on screen. In terms of cinematic language, the magical thinking that purports to have a psychic influence over others transforms into the conviction that I am privy to the thoughts of those who appear in the film-image. The close-up is, perhaps, the most salient cinematic device to support this fantasy, especially when, in connection with reverse shots, we are called upon to share one and then another character's subjective gaze.

Freud's special emphasis on animism is, therefore, seminal for my own discussion because it is what is common to all uncanny viewing effects. Be it a belief in the return of the dead, in the division and interchangeability of the double, or in the power of one's psychic life, it is also at the heart of cinema's affective effect. As Freud concludes, 'an uncanny effect is often and easily produced when the distinction between imagination and reality is effaced, as when something that we have hitherto regarded as imaginary appears before us in reality' (Freud 1955: 244). This is as true for film characters who indulge in their fantasies by enacting them with their own body as it is for us sharing in such magical thinking. Such a doubling between Gothic themes and cinematic techniques ultimately revolves around the fact that both - the film's story and the effects that its mise-en-scène and editing have - are predicated on seeing something out of the ordinary, even if it remains uncertain whether this apparition is real or not. Along with the visceral engagement of the hero and heroine, that of the audience hinges on taking such blurring of the boundaries between imagination and reality to a fundamentally Gothic excess.

Alfred Hitchcock, the master of the thriller genre, is a paradigmatic example for the Gothic at the heart of film and film theory precisely because he is working in direct line with the pre-cinematic and Gothic phantasmagoria. Being preoccupied with uncanny disturbances of the ordinary - haunting, doubles, madness and murder - he not only uses the psycho-thriller to develop his singular vision as a film-maker, he also self-consciously reflects and reflects upon the Gothic inheritance of the cinematic medium per se. The manner in which his films produce suspense makes use of narrative uncertainty in more than one sense. The outbreak of something strange not only unsettles the familiar everyday in his pictures. Hitchcock also deploys a disruption of the seamless construction of coherent space which continuity editing is meant to afford, producing a disturbance of ordinary vision. The outbreak of excessive emotion and violence around which his narratives circle may be doubled by top-down or bottom-up shots that distort the appearance of the characters, or by a pronounced use of shadows, reminiscent of the also Gothic film noir of the 1930s-1940s, that enmesh them in an imaginary web. Such disruption is usually, however, also accompanied by camera work and editing that draws attention to itself. We are not only meant to notice that something has gone awry with the hero's or heroine's perception of the world, we are also meant to realise that what we see on screen is the result of technical artifice, not a mimetic representation of the world. We are thus left in an aporia, suspended between sharing emotionally in the intense excitement of the characters and taking notice intellectually of the visual devices that produce this suspense. We are caught up equally in the obsessions of the characters and in Hitchcock's obsession with the cinematic techniques that produce intense affects effectively.

Indeed, Gothic excess in Hitchcock's oeuvre has, above all, to do with the way the camera is deployed to produce a visual enchantment that is tantamount to robbing us (along with the characters) of any ordinary vision of the world. The opening credit sequence of Vertigo (1958), a film that revolves around a woman allegedly haunted by her suicidal ancestor, draws our attention from the start to the way the spectral vision the film narrative is about to present is concerned with a manipulation of our eyes. While a close-up shot initially focuses on a woman's mouth, across which the name of the main actor, James Stewart, appears, it soon glides upwards along the nose to capture a pair of eyes, moving cautiously from the right to 
the left. Once they have come to rest, staring straight at us, the name of the female star, Kim Novak, appears just beneath them. Then, as the camera zooms in on the left eye, the words 'in Alfred Hitchcock's' pop up in the same lettering to indicate his authorship, while also bringing with it an even closer move towards the woman's eye.

Now, filmed through a red filter, this eye is wide open, as in fear, but also so as to allow the film's title to emerge from the pupil. The word 'Vertigo' is soon followed by a purple spiral, which is initially superimposed over the shape of the pupil and iris it replicates, until, having filled the screen, it blocks out the woman's eye completely. In its stead, a series of revolving circular shapes in different colours, now accompanied by Bernard Herrmann's billowing score, emerge from a black backdrop and keep moving forward from the centre of the screen where the woman's eye used to be. Even as their vertiginous movement sets the tone for the hero's obsessed gaze at the heroine, it produces for us a double vision. In our mind, we retain an after-image of the woman's eye, which has been displaced by the circular shapes that recall it, until they are, once more, reabsorbed by it. In other words, as part of Hitchcock's self-reflection, the image of the eye and the geometric shapes replace each other, even while blurring the boundary between realistic and abstract cinematic representation. The woman's eye engenders shapes while she is also subsumed by them. The final shot of the credit sequence returns to an extreme close-up of the woman's eye, once more captured through a red filter. Gazing at us, although now no longer wide open in fear, it serves as the source for the words 'directed by Alfred Hitchcock' that emerge from it. Epistemological uncertainty remains, as it often does in Gothic tales where we cannot tell the actual status of spectres (are they supernatural or mental projections?). Is the woman's eye the object of the director's gaze, or is her vision equated with his? Does he control her gaze (the shapes emerging from and reabsorbed by her vision), or is he the product of her eye? And what are we meant to anticipate, given that the hero, aligned in words with the woman's mouth, is not part of this visual game?

The film narrative itself discloses the lethal core at the heart of all this ghost-seeing. Scottie Fergusson, a retired SFPD detective, takes on the job of watching over the beautiful Madeleine Elster, because her husband has convinced him that, haunted by her ancestor, mad Carlotta, she has become suicidal. After she subsequently succeeds (it appears) in jumping from the tower of a Spanish mission close to San Francisco, Scottie falls into a deep depression. Then, upon meeting Judy, who uncannily resembles the dead woman, his obsession for her takes a new turn. Compelling her to become Madeleine for him, to put on her clothes and change both her hairstyle and her make-up, he hopes to resuscitate the dead woman at the expense of the separateness of the one still living. The suspense of the story, in turn, hinges on the fact that Hitchcock lets us in on the ruse that has been played on his clueless hero. Judy is actually an actress, who is playing Madeleine at the behest of Gavin Elster, so that he can kill his wife. Knowing that Scottie has been suffering from vertigo, Gavin and Judy are sure he will never make it to the top of the church tower to discover that the woman he loved as Madeleine was not a suicidal ghost-seer but rather the scheming double of Elster's real wife. When, upon discovering the deception, Scottie forces Judy/Madeleine to return to the scene of the crime, his repetitioncompulsion takes on yet a further Gothic turn. Because Judy sees a darkly clad figure emerging from the stairway, she does fall from the tower, thus fulfilling her impersonation of the luckless wife, even while, as in several horror stories by Poe, she turns into a ghost that will now forever haunt the man who has hunted her down.

At various moments in Vertigo, meanwhile, Hitchcock uses the Gothic motif of the revenant to speak to the lethal power of his camera. The premise of Elster's murder plot, after all, consists in Judy not only posing as his wife, but remodelling her appearance along the lines of the portrait of mad Carlotta hanging in a museum - a device, again, reminiscent of those portraits that come to life in Gothic fiction. Madeleine is thus the double not of an actual woman but of an imaginary one, modelled Gothically on a painting. Hitchcock's camera, in turn, repeatedly catches Madeleine in poses that present her performance of a haunted woman as a tableau vivant performed - in a flower shop, at Carlotta's grave, in front of her portrait in the museum, at the window of a hotel - exclusively for Scottie's eye. In the first part of the film, the performed illusion is twofold. While Scottie is oblivious to the fact that Madeleine knows he is following her and is posing only for him, we also are cajoled into perceiving her as a woman suspended uncannily between a portrait and its embodiment.

The epistemological uncertainty posed by the faux ghost story at the start of the film also speaks to the spectral power of cinematic representation itself. Hitchcock uses the other woman in Scottie's life, his maternal friend Midge, to debunk his hero's obsession, even while disclosing the artifice of his own medium. One evening, after Scottie has driven her home, Midge, mocking his belief in ghosts, leaves him sitting in his car and threatening to take another look at the portrait. Suddenly uncertain himself, Scottie picks up the museum catalogue he has tucked away beneath the dashboard and opens it to the relevant page. The editing segues into a cinematic performance 
of Scottie's ghost-seeing. In a lap dissolve, the profile of Madeleine comes to be juxtaposed over the black-and-white reproduction of Carlotta's portrait in the catalogue, only to once again fade. The double vision sustains the uncertainty about whether Madeleine embodies an uncanny resuscitation of the dead woman on which Scottie's necrophilial desire thrives.

At the same time, we are called upon to remember that this profile is, in fact, the same shot as the one at the climax of the scene when Scottie saw Madeleine for the first time at Ernie's restaurant. So as to underscore that his hero privileges an imagined picture and not a direct view - of the woman he is to follow, Hitchcock has Scottie turn away from Madeleine as she approaches the bar where he is sitting. When she finally comes to stand in profile directly in front of the camera, her pose is one performed not for him but for us. The image that Scottie's enchanted eye juxtaposes over the reproduction in the catalogue, in his effort to cast aside the doubt Midge has raised, is consequently not one he remembers. What appears to be his subjective gaze is, in fact, Hitchcock's signal that he is playing with our vision.

This break in the diegesis that foregrounds its artifice corresponds to the fact that the woman who shows herself in profile at Ernie's restaurant is not Madeleine posing for Scottie, since she has noticed that he has turned his back to her and cannot see her. Rather, this is an extradiegetic shot, in which the star, Kim Novak, presents herself to us as the director's new leading lady. Then, too, the lap dissolve melds together the reproduction of a painted portrait with the reappearance of a previous shot. Scottie's hesitation over whether the woman he has fallen in love with is real or a ghost is thus doubled by our own hesitation over whether this face belongs to a fictional character or is an image detached from the diegesis to highlight the film's enactment of stardom. Scottie treats this composite image as proof of Madeleine's haunting. By using not the hero's memory image but rather a recycled shot, moreover, Hitchcock robs us of our ocular certainty. What is the status of this double portrait? Is there any reference adhering to it or is it a free-floating, cinematic image? The Gothic excess that Hitchcock self-reflexively taps into makes us see the fabrication, yet we are nevertheless taken in by its charm.

In Hitchcock's film of Daphne du Maurier's Rebecca (1940), the return of a dead woman does not so much involve an enchantment of the heroine's eye as reveal her willingness to be engulfed by the imagined body of this predecessor. Since the housekeeper at Manderley, Mrs Danvers, not only staunchly keeps alive the memory of Maxim de Winter's first wife but also imposes this spectral presence on to his second wife, the distinction between psychic and material reality blurs in this film more and more. Yet, as befits the Gothic mode of the original novel, uncertainty pervades this spectral haunting. Is the heroine, who throughout the film has no given name, the victim of a dead woman's malice, or is this ghost an expression of her own death wish? Is Rebecca really haunting Manderley or is her presence merely a fantasy that Danvers and then the second wife entertain? Is the fantasy that Rebecca is trying to evict her from her uncanny home in fact the heroine's recasting of her troubled marriage in Gothic terms, sometimes in a dream-state?

In Rebecca, the engulfment by a spectral force, which aligns the spectator's emotional position with the heroine's dream-work, becomes particularly noticeable in the self-reflexive use to which Hitchcock puts lap dissolves. During the heroine's whirlwind romance with Maxim de Winter, many of the transitions from one scene to the next are signalled by a juxtaposition between the ending of the former and the beginning of the latter. As the heroine comes closer to Manderley, however, what up to that point was nothing more than an editing convention takes on real significance for the plot. To mark the period of time that passes between her perfunctory marriage ceremony in the south of France and her arrival at her new home, Hitchcock offers a poignant visual juxtaposition. The bunch of flowers that Maxim buys just before they drive off is so enormous that it covers not only her upper body but also half of her face. In the lap dissolve that follows, this half-hidden face is, in turn, superimposed on the iron gate that the heroine had dreamt about passing through like a spirit in the narrative frame that begins the whole film. Now her face fades into the bars just before the servant, noticing the approaching car, opens the two gates to let their car pass through. By merging these two distinct images - the bride's head and the gated entrance to the estate - the lap dissolve produces a non-mimetic representation that anticipates the heroine's uncanny absorption by and into the mansion at the end of the drive. The ambivalent manner in which she both fades into this edifice even as it emerges from her head suggests that what is about to happen is as much the product of her imagination - and of lap dissolve and editing - as it is a threat to her existence.

Even more eerie is the transition between the moment when Danvers draws her mistress's attention to the portrait of Lady Caroline hanging in one of the dark hallways in Manderley and the costume ball where the second Mrs de Winter will wear this 
ancestor's dress, not knowing that Rebecca had chosen the same outfit the year before. While the heroine, dwarfed by the enormous painting, walks out of the frame, the camera pans towards the painted woman. Then, as her painted body fades out, an image of the nocturnal mansion, shot from the same angle as in the film's opening frame, fades into view. The uncanny impression effected by the visual juxtaposition is that Rebecca is hovering over the house. As such, this lap dissolve anticipates that Rebecca will not be displaced by any impersonator, even an unwitting one. After Maxim demands that his wife take off the tell-tale costume, the festivities are, indeed, interrupted because the boat containing Rebecca's corpse has suddenly re-emerged from the sea. The evidence of foul play to which this material return from death speaks further underscores the power that the dead woman continues to hold over the de Winter mansion.

The fact that an invisible force seems to draw the camera to Lady Caroline's portrait, however, also speaks to the way Hitchcock makes use of the space that is offscreen throughout Rebecca to produce some of his most pointed Gothic effects. Early on in the film, Danvers shows the heroine the door leading to Rebecca's room, invoking its magnificence. Then, while both women, as if suddenly in a trance, walk out of the frame, the camera proceeds towards the door. For a brief moment, the dog guarding it raises its head but, as if to signal that the figure approaching is not a stranger, it does not stir. The lap dissolve, juxtaposing this portentous door with the napkin bearing Rebecca's initials, supports the effect that the person whose gaze the camera is transmitting at this point is that of the dead woman herself. Rebecca's offscreen presence is, furthermore, repeatedly invoked by Danvers as she tries to convince the unwelcome second Mrs de Winter that her predecessor has come back to watch the living - and in so doing compelling us to imagine her being there as well, just as we are doing with the insubstantial figures on the screen.

Maxim does the same in the scene at the boathouse, during which he confesses to his wife the violent argument that he had with Rebecca on the night of her death. As Hitchcock's camera pans around the room, re-enacting the dead woman's movements, she is resuscitated as the spectral object of our gaze. Once he has reached the point in his confession when he recalls that at the height of her taunting remarks she had come to stand face to face with him, the camera itself has come full circle and is now also facing Maxim. For a brief moment, as Maxim finishes his story by describing how he struck her, Rebecca's ghost is no longer the invisible object but rather the gaze behind the camera. The reverse shot focuses on the spot where she stumbled and fatally fell, followed by a shot that now brings the transfixed gaze of the heroine into play. If she is fully absorbed not only by her husband's tale but also by the magical evocation of Rebecca's ghost, she is also the one to put an end to the spectacle by realigning our gaze with hers. It is this moment at which we recognise that we have been captivated by a cinematic ploy that not only allowed us to imagine Rebecca's spectral presence, but more importantly to gaze with her at all those still living, turning us into ghosts as well. The Gothic motif of a woman who returns from the dead to haunt those who have survived her thus allows Hitchcock to exploit the phantasmagoric possibilities of the cinematic medium that have always been basic to the Gothic too, even while drawing us into the force-field of this illusion.

The psycho-thriller Suspicion, in turn, which came out one year later, also starring Joan Fontaine, can be read as a counter-piece to Rebecca. While the Gothic mode here, too, supports the heroine's path to self-knowledge, at issue is less the psychic torment resulting from a young bride's imaginary rivalry with her dead predecessor and more a young bride's uncertainty about whether she may have married a murderer. Rather than indulging in the fantasy of being haunted by the past, Lena's excessive fantasy pertains to a danger that is possibly still to come. Her hallucinations allow her to experience crimes that have not yet been committed as spectral events taking place before her inner eye. The minute she begins to doubt the integrity of her spendthrift husband, Johnnie Aysgarth, by linking his irresponsible attitude towards money (including an act of embezzlement) to a perhaps unlawful killing, the suspense of the narrative falls back on her. We are less concerned with when he might kill her. Our uncertainty revolves instead around whether she is right in assuming that he is the danger she imagines him to be.

The mood of uncertainty is fostered in part because her new home is rendered as a Gothic site even if it is not as architecturally 'Gothic' as Manderley. From the moment the newlyweds move in, interwoven shadows cover the walls of the entrance hall, as though the characters are caught in a web. As the heroine's paranoia becomes more intense, so too the shadows grow more pronounced, taking over the entire house. Employed as an architectural double of her psychic doubt, the grid on the walls that Lena keeps passing by intensifies the contrast between the imagined darkness inside the house and the brightly lit reality outside. The psychic hesitation they effect is that, 
as in Rebecca, it not only remains uncertain whether the threat they render visible is first and foremost her projection. Equally ambivalent is whether this imaginary prison is one that she has become caught in or one that she is producing and projecting on to her husband. This, again, is Hitchcock's self-reflexive comment on the way his camera work imprisons us in his heroine's excessive imagination even while showing his sleight of hand.

As in Rebecca, Lena's excessive absorption in her fantasy work corresponds with an excessive disturbance of continuity editing; it is only in Suspicion, though, that uncanniness becomes self-reflexive, particularly regarding the very power of reanimation so central both to the Gothic and to the cinematic medium. At one point in the mounting tension between this young couple, Johnnie sharply forbids Lena to intervene in a business venture he intends to carry through with his friend, Beaky. She has already begun to harbour the fantasy that her husband is merely using their plans to develop a piece of coastal land as a way to get at his clueless friend's money. A Scrabble game the following evening is introduced with a lap dissolve, in which the truncated word 'doub' is juxtaposed over Lena's puzzled face. Then, as the two men discuss going to the site early the next morning, she begins to put together the word 'murder' from the pieces lying face up on the table. Hitchcock's montage produces a phantasmagoria on screen, again recalling magic-lantern Gothic, in which the inanimate letters, in conjunction with a photograph of the coastal road, become animated. As a close-up of Lena's excited face is superimposed over the photograph, the still image transforms into a live backdrop in a brief sequence showing Johnnie pushing Beaky off the cliff. Drawn completely into his fall and the turbulent waves about to swallow him up, both juxtaposed over the close-up of her face, we share her lethal thoughts, as if gifted with the magic of telepathy. Overwhelmed by her own enjoyment of this imagined death, which she (and we) experience by proxy, she faints. The falling of her body puts an end to both her excessive fantasy and the excessive montage.

The climax of this uncanny animation of objects in Suspicion is, of course, the famous scene in which Johnnie carries a glass of milk up the stairs, while Lena, waiting for him in her bedroom, is convinced that he has found a poison that cannot be detected after death. Functioning as the reverse shot to her gaze, we see the portentous glass first as a shadow on the completely darkened floor of the entrance hall, cast by the light from the kitchen, which, upon entering, Johnnie immediately extinguishes. Even if the scene is an enactment of what Lena imagines is happening outside her door, the
danger is staged only for us. Thus, danger is staged only for us. Thus, as Johnnie walks up the stairs in the darkened hall, the milk glass now alone shines luminously; it face is indistinguish its secret force only for the audience, while his face is indistinguishable in the darkness. Given that, by virtue of an rative, it remains we share Lena's thoughts throughout the film narrative, it remains uncertain whether this scene actually takes place or is happening only in her mind. We are drawn into her fantasy, even when she is not explicitly present. If this is Hitchcock's joke on us, it is also a reflection on the inherently Gothic rhetoric of cinema.

The most uncanny of all houses in Hitchcock's oeuvre still has to be the home of Norman Bates in Psycho (1960). Reminiscent of many a haunted house in black-and-white cinema, while it also recalls Edward Hopper's painting House by the Railroad (1925), it is another Gothic reanimation of what was already a spectral picture. As in Rebecca, moreover, this house is the scene where a dead woman has returned so as to haunt the living, although, in this case, the house contains the spirit, as well as the skeleton, of the murdered mother, kept alive thanks to her son's impersonation of her. If the point of his double act is that it allows him to kill in the guise of the mother he himself killed, then the distinction between the murdered woman and the murdering man collapses into a hybrid body. The inanimate maternal fetish that Norman has preserved, hiding it in the cellar when visitors threaten to come, is not attached to the scolding woman's voice which the hapless heroine, Marion Crane, hears emanating from the house. The ventriloquism pertains to the house itself, which seems to be alive, the windows appearing like eyes looking down at her. As in Suspicion, this home's uncanny effect draws attention to the fact that for us it exists mainly as the effect of the psychic reality of the deranged hero.

But if, with Norman's voyeurism, which culminates in his gaze through a hole in the wall at the naked Marion about to step into the shower, we return once more to the issue of enchanted eyes at the centre of Vertigo, what also looms in Psycho is Hitchcock's idiosyncratic mix of Gothic terror and self-reflexive comic wit (itself like that oxymoronic condition of the Gothic as early as Walpole's Otranto). In the final scene, Norman sits alone in a locked room in the County Court House. Once again the camera, like a spirit, has passed through a barred door and is alone, facing not Manderley, as in the opening sequence in Rebecca, but the face of a lonely young man. Once more a female voice-over offers a narrative commentary as the camera slowly pans towards the object of her discourse. Only 
now, in contrast to the narrating heroine in Rebecca, this voice is attached to the body about which she speaks. What Hitchcock, once again, appeals to is our Gothic belief in animism, allowing us to share in the thoughts running through this hybrid figure's mind, fusing son and mother. Then, once more relying on an excessive disturbance of continuity editing to suggest a disturbance of normality, the body that is host to this spectral voice transforms into a composite image that is pure cinematic virtuality. As the camera moves into a closeup, capturing Norman's face, his intense, inward gaze transforms into the grin of a madman. At that point, the illusory reanimation of the maternal fetish, as in the climactic cellar scene where Norman is finally caught, is now superimposed over this grimace. Just as in Vertigo, the lap dissolve not only juxtaposes two separate images, but, by recycling an earlier sequence, two temporal moments.

Cinematically what is staged in the final lap dissolve of Psycho is a double birth. Norman's face fades out, replaced for a few seconds first by the face of the maternal fetish and then by a car (Marion's) being pulled out of the swamp behind the motel. If the son has died off completely, he has given birth not to the actual mother, but to the fetish body he had created along with Marion's corpse, now contained in the car, with its two front lights becoming a face of sorts. This montage recalls Rebecca's dead body, emerging once more from the sea, indicating not only that the dead will return over and again on screen, but that as such we are dealing with a form of spectral recycling. The final title in Psycho, 'The End', puts closure, not to the haunting, but to the visual excess, detached from all mimetic reference. As the screen turns black before the car has been fully retrieved, Hitchcock signals a theoretical position basic to the Gothic and to cinema alike. The kernel of excessive enjoyment can never be fully disclosed. It moves from body to body, from film image to film image, gaining ever more layers of articulation along the way. Psycho is Hitchcock's cinematic Frankenstein-ian monster, an amalgamation of visual fragments and story partly taken from previous films and images. In this overdetermination of spectral images superimposed, the Gothic at the heart of film and film theory finds its perfect articulation.

\section{References}

Bronfen, Elisabeth (2016), Mad Men, Death and the American Dream, Chicago: University of Chicago Press.

Castle, Terry (1995), The Female Thermometer: Eighteenth-Century Culture and the Invention of the Uncanny, New York: Oxford University Press.
Cavell, Stanley (1979), The World Viewed: Reflections on the Ontology of Film, Cambridge, MA: Harvard University Press.

Freud, Sigmund (1955) [1919], 'The Uncanny', in The Standard Edition of the Complete Psychological Works, ed. and trans. James Strachey, London: Hogarth Press, XVII, pp. 217-56.

Hitchcock, Alfred (dir.) (1940), Rebecca, Selznick International Pictures/ United Artists.

Hitchcock, Alfred (dir.) (1941), Suspicion, RKO Pictures.

Hitchcock, Alfred (dir.) (1958), Vertigo, Paramount Pictures.

Hitchcock, Alfred (dir.) (1960), Psycho, Paramount/Universal Pictures.

Weiner, Matthew (creator) (2007-15), Mad Men, Weiner Brothers/Silvercup Studios/Lionsgate Television. 